\title{
Olympic reports
}

\section{Lessons learnt at the 1996 Atlanta Olympic Games}

\begin{abstract}
The medical preparation of the team began well before the opening of the Games in Atlanta, but there is little doubt that resources were limited and in retrospect there is also little doubt that more will need to be provided if we are to do any better in the Sydney Games in 2000. The British Olympic Association organised a number of multisport preparation camps in Tallahassee, including a pre-Olympic preparation camp which opened on 1 July 1996. The purpose of this was to allow acclimatisation. It also provided an opportunity for more structured medicals, for more careful medication review, and for better acclimatisation than would have been possible without such a camp.

There were three headquarters (HQ) doctors based in Tallahassee and five more in Atlanta. These included six primary care clinicians with a diploma in sports medicine, one consultant respiratory physician, and one consultant orthopaedic surgeon. Eight of the Olympic teams took their own doctors with them.
\end{abstract}

\section{Prevention}

A medical examination before the Games was completed in only $60 \%$ of the track and field athletes. This compared with a figure of $98 \%$ in all the other Olympic sports. A medical review form completed by the athletes showed that a number were carrying substances with them which, if taken, might well have banned them from competition.

\section{Organisation}

From a medical practitioner's perspective, the Games were well organised. The polyclinic provided excellent service and our host colleagues could not have been more helpful. At a very early stage we won an agreement that British athletes would not be seen without first being referred by one of the HQ medical team. This discouraged any athlete from securing a second or even third opinion. We also agreed treatment protocols among ourselves for the same reason.

As detailed in the $\mathrm{HQ}$ popular press there were a number of problems with transport, making it difficult for HQ doctors to cover more than one sport in a day, let alone the three or four for which each of us was responsible. We made sure that there was always one doctor in HQ between 7.00 am and $11.00 \mathrm{pm}$ supported by another mobile $\mathrm{HQ}$ medical officer available within the Olympic village. Initially, we planned to hold surgery between 8.00 and 9.00 each morning and evening, but it soon became clear that these plans were redundant because the athletes simply came for consultation at times which best fitted in with their training schedules or competition. These fixed times were instead used for meetings between the $\mathrm{HQ}$ doctors, team doctors, sports psychologists, physiotherapists, and other paramedic staff. In the event, this was time very well spent with open friendly discussions taking place between all members of the support staff and between all disciplines. Our proximity to the physiotherapy room provided certain problems as this was a noisy and busy place throughout most of the working day. Problems arose when individual athletes had a particularly sensitive problem or were looking for privacy.

The accommodation was extremely cramped and the air conditioning provided an opportunity for the spread of an upper respiratory infection. Sore throats began to appear within three days of the athletes arriving in the Village, reaching a peak of 10 new cases a day by day 15 . The polyclinic amazed us by reporting the result of throat swabs within two hours of delivery. Streptococcal infection was excluded by DNA extraction rather than by culture on blood agar.

The polyclinic scored again with the quality and breadth of the investigative procedures including $x$ rays, ultrasound, magnetic resonance imaging, and computed tomography scanning. On the down side was the long journey on the land train, taking between 30 and $45 \mathrm{~min}$ utes to the clinic and another 45 minutes back. These meant that any athletes needing escort took a doctor out of commission for almost half a day. We circumvented this problem to an extent by commandeering a bicycle. This also had its down side with more injuries to $H Q$ medical officers than occurred among the athletes themselves!

The opening and closing ceremonies were spectacular as always, marred by the death of the Polish Chef de Mission who had a myocardial infarction shortly after arriving on the track with his team for the opening ceremony.

The Games were full of great success but also great disappointment. One lesson learnt was that it is extremely dangerous to predict our gold medal winners and the medal tally.

\section{Key points}

- Ensure medicals are done early and review just before the Games, paying particular care to medication review

- Work closely with all other medical and paramedical staff

- Build up a good relationship with the host country's medical support.

RICHARD BUDGETT MARK HARRIES JOHN ALDRIDGE ROD JAQUES D E JENNINGS 